GLOBAL JOURNAL OF EDUCATIONAL RESEARCH VOL 18, 2019: 9-13

COPYRIGHT@ BACHUDO SCIENCE CO. LTD PRINTED IN NIGERIA. ISSN 1596-6224

www.globaljournalseries.com; Info@globaljournalseries.com

\title{
DETERMINANTS OF EFFECTIVE IMPLEMENTATION OF UNIVERSAL BASIC EDUCATION PROGRAMME IN IKOM EDUCATION ZONE OF CROSS RIVER STATE, NIGERIA
}

AGBOR, CATHERINE ALEX

(Received 16, October 2017; Revision Accepted 10, September 2018)

\begin{abstract}
This study examined the determinants of effective implementation of Universal Basic Education Programme in Ikom Education Zone of Cross River State, Nigeria. Two research questions were posed to guide the study. Relevant literature was reviewed based on the variables of the study. Descriptive survey design was adopted for the study. The population of the study was made up of all 4,508 public primary school teachers and all the 345 public primary schools in the area while the sample size was 468 public primary school teachers and 156 public primary schools. In selecting the sample for the study, a multi-stage sampling technique was adopted involving stratified random sampling, purposive sampling and accidental sampling. Data was collected for the testing of the two research questions through the use of questionnaire, checklist and secondary source, from State Universal Basic Education Board and analyzed using SPSS. The result of the analysis revealed that instructional monitoring and supervision in schools is poor as only Head teachers do the bulk of monitoring and supervision of instruction. The results further revealed that record keeping practices in schools was below standard. Based on these findings, recommendations were made
\end{abstract}

KEYWORDS: UBE Programme, Ikom Education zone, instructional monitoring, supervision, record keeping.

\section{INTRODUCTION}

Education system in Nigeria before 1999 was six year primary school, three year junior secondary and three year senior secondary school. But in an attempt to encourage pupils to stay in school, and learn appropriate skills that will make them self-reliant, the compulsory nine year basic education programme was introduced.

Arising from this new idea of basic education, the Universal Basic Education (UBE) programme was launched in Nigeria, and was in line with the actualization of other many international conventions. One of such is the World Conference on Education for All (WCEFA), held in Thailand (1990), which emphasized access, retention, success, quality, efficiency and equality in education (UNESCO, 2002). In response to the Jomtien Declaration on Education for All, the Federal Government launched the UBE programme with reducing the incidence of dropout from school, catering for learning needs of young person's etc as part of its objectives (Obanya, 2012).

In spite of these laudable objectives of the programme (FRN, 2004), the big question that readily comes to mind tends to be how these objectives can realistically be achieved. Little wonder the Nigerian government pointed out that about a large percentage of Nigeria children still have no access to basic education, and that majority of those that manage to be in school are given poor quality education. It is therefore

Agbor, Catherine Alex, Arts Education Department University of Calabar, Calabar, Nigeria.

(C) 2019 Bachudo Science Co. Ltd. This work is licensed under Creative Commons Attribution 4.0 International license. 
obvious that there are still problems and challenges inhibiting the effective implementation of UBE in Nigeria despite government's efforts. It is this that has motivated this research to determine variables of effective implementation of UBE programme for possible explanation. The determinants focused in this study are monitoring and supervision of instruction; and record keeping practices.

In terms of monitoring and supervision of instruction, those particular activities and aspects which maintain and promote the effectiveness of teaching and learning in the school as far as universal basic education is concerned are teachers, heads of departments and sectional heads. In the aspect of record keeping, school records do not only enable the school administration to have a clear picture of what is available and what is required, they also provide justification for certain needs and seems to extend the memory by which persons or schools can pass information and achievement to future generation.

It is against this background that the research investigates school variables influence on implementation of UBE programme.

\section{RELEVANT LITERATURE}

Literature reviewed defined school record as a unified, comprehensive collection of documentation concerning all services provided to a student which may include intake information, evaluation(s), assessment(s), releases of information forms, individual learning plan and all written notes regarding the student (Harch, 2006). Chifwepa (2001) which noted that records do not only enable school administrators to have a clear picture of what is available and required, they provide justification for certain needs and deem to extend the memory by which persons and/or organizations can pass on their culture and achievement to the future generations, stressing that the content and quality of the school records can serve as a direct reflection of the amount of work that has been expended on the school enterprise.

Nwaogu (2004) noting that if instructional supervision is the process of working with people who are working with pupils to bring about improvement in instruction, then it is very important for an instruction supervisor to be selected based on his/her competence and professional knowledge in that art of instruction so as to be able to influence, facilitate, direct and motivate the teacher efficiently and effectively to improve teaching/learning in UBE education satisfactorily. Also, Mkpa's (2004) study revealed that monitoring and supervision of UBE programme in Uyo Education zone of Akwa Ibom State, Nigeria was poor.

\section{STATEMENT OF THE PROBLEM}

Government has remained committed to developing in its citizenry, sensitivity for education. Unfortunately, it seems all is not well with the implementation of this programme as complaints are rife amongst educationists and members of the public in the country about the state of primary education in Ikom Education zone in particular and the nation in general. For instance, fees and levies are charged by some schools when there should be no charges as far as UBE policy is concerned. Monitoring and evaluation units have revealed the sorry state of infrastructural facilities, classrooms, instructional materials etc. in schools. The situation is worrisome, hence this research.

\section{RESEARCH QUESTIONS}

To give the study a proper guide, the following research questions were raised:

1. What is the extent of monitoring and supervision of instruction in the implementation of UBE programme in Ikom Education zone?

2. How effective are records keeping in the implementation of UBE programme in lkom Education zone?

\section{METHODOLOGY}

The research design adopted for this study was the descriptive survey, while the population of the study consisted of 345 public primary school and 4,508 teachers in the schools in Ikom Education zone. The study adopted a multi-stage sampling technique and came out with a sample selection of 156 public primary school and 468 teachers.

Data was collected for the testing of the research questions through the use of a researcher designed questionnaire and a checklist on material resources from the State Universal Basic Education Board. They were well validated by experts in research measurement and evaluation and administered to all respondents within the study area. Simple percentages were used for data analysis with the use of SPSS.

\section{RESULTS}

The results presented were based on each research question as follows:

1. Research question 1: What is the extent of monitoring and supervision of instruction in the 
implementation of UBE programme in Ikom Education zone?

In order to answer this research question, the information collected on the extent of monitoring and supervision of instruction in the implementation of UBE programme was subjected to percentage analysis. Details of the analysis are given in Table 1.

Table 1:

Monitoring and supervision of instruction in the implementation of UBE programme

\begin{tabular}{lcc}
\hline Instructional Monitoring and Supervision & Frequency & Percentage \\
\hline Teachers' submission of weekly plan to head teacher & 155 & 33.1 \\
Head teachers' weekly assessment and correction & 128 & 27.4 \\
Head teachers' classroom assessment & 99 & 27.4 \\
$\begin{array}{l}\text { Local Government Area Education Authority monitoring and } \\
\text { supervision }\end{array}$ & 61 & 21.2 \\
SUBEB board officials monitoring and supervision & 25 & 13.0 \\
Total & 468 & 100 \\
\hline
\end{tabular}

Source: Fieldwork (2018)

Results in table 1 revealed that teachers' submission of their weekly lesson plan to their head teacher has the highest percentage with $33.1 \%$ while head teachers' weekly assessment and correction has $27.4 \%$. Head teachers' classroom assessment has $21.2 \%$, monitoring and supervision by Local Government Area Education has $13.0 \%$ while monitoring and supervision by State Universal Basic Education Board has $25 \%$. This in essence shows that teachers' submission of their weekly lesson plan to head teachers $(33.1 \%)$ is the most effective and efficient way of monitoring and supervising of instruction in the implementation of UBE programme.

2. Research question 2: How effective are records keeping in the implementation of UBE programme in lkom Education zone?

In order to answer this research question, the information collected on the extent of effective record keeping in the implementation of UBE programme was subjected to percentage analysis. Details of the analysis are given in Table 2. 
Table 2:

Effective record keeping in the implementation of UBE programme \begin{tabular}{l|ll}
\hline Effective record keeping & Frequency & Percentage
\end{tabular}

Pupils' portfolio

Checklist inventory

Pupils' monthly report

Observation notes about pupils

Pupils' personal file

Total
51

153

137

53

74

468
10.9

29.3

11.3

15.8

10

Source: Fieldwork (2018)

Results in table 2 revealed that checklist inventories have highest percentage with $32.7 \%$ while pupils' monthly report has $29.3 \%$. Pupil's personal file has $15.8 \%$. Observation notes about pupils have $11.3 \%$ while pupil's portfolio has $10.9 \%$. This in essence shows that checklist inventories and pupils' monthly report $(32.7 \%$ and $29.3 \%$ ) are the most effective and efficient record keeping practices which could contribute to the implementation of UBE programme.

\section{DISCUSSION}

Discussion of results is presented as follows:

Monitoring and supervision of instruction in the implementation of UBE programme

For effective and efficient implementation of the UBE programme, all the personnel from classroom teachers to the SUBEB officials must contribute equally in the implementation of the programme. This result is in consonance with the findings of Nwaogu (2004) noting that if instructional supervision is the process of working with people who are working with pupils to bring about improvement in instruction, then it is very important for an instruction supervisor to be selected based on his/her competence and professional knowledge in that art of instruction so as to be able to influence, facilitate, direct and motivate the teacher efficiently and effectively to improve teaching/learning in UBE education satisfactorily.

\section{Effective record keeping in the} implementation of UBE programme

Record keeping as observed in the result shows that there is a dearth of records in the school system which if provided would enhance effective and efficient implementation of UBE. This result is in agreement with the findings of Chifwepa (2001) which noted that records do not only enable school administrators to have a clear picture of what is available and required, they provide justification for certain needs and deem to extend the memory by which persons and/or organizations can pass on their culture and achievement to the future generations, stressing that the content and quality of the school records can serve as a direct reflection of the amount of work that has been expended on the school enterprise.

\section{CONCLUSION}

The findings in this study revealed that the UBE programme has still not achieved some of its goals; instructional monitoring and supervision in schools is poor, especially by both local government education authority and the state schools board. 


\section{RECOMMENDATIONS}

Based on the findings, successful implementation of the UBE programme requires more efforts by the head teachers, local government authority and state universal basic education board in monitoring and supervision.. Also records keeping are essential aspect of the programme implantation, for without which, no success or failure can be ascertained. To achieve these more statutory orientation courses, seminars, conferences and workshops to equip those concerned should be organized on timely basis.

\section{REFERENCES}

Chifwepa, V. 2001. Monitoring records at school level. Retrieved December, http://www.adeant.org/adeaportal/adea/d ownloadcentre/NESIS/E-record021065.pdf

Federal Republic of Nigeria 2004. Approved guidelines for assessing and utilization of the FGN-UBE Intervention Fund, Abuja: UBEC.
Harch, D. 2006. Record keeping and confidentiality for ABLE administrators. Retrieved from http://www.pde.state.pa.us/able/lib/fieldn ote06/fn06records.pdf.

Mkpa, M. A. 2004. Supervision of instruction in the implementation of UBE in Uyo Education zone of Akwa Ibom State: An analytical perspective. Journal of Education Management. 2(!), 91-99.

Nwaogu, J. I. 2004. Aguide to supervision in instruction in Nigerian schools. Enugu. Forth Dimension.

Obanya, P. 2012. Revitalizing education in Africa. Nigeria: Stirling-Horden Publishers.

UNESCO 2002. Education for all: is the world on track? EFA Global Monitoring Report. Paris: UNESCO. 